\title{
Specific antigen(s) in sarcoidosis: a link to autoimmunity?
}

\author{
Gernot Zissel and Joachim Müller-Quernheim \\ Affiliation: Medical Center - University of Freiburg, Center for Medicine, Dept of Pneumology, Freiburg, \\ Germany. \\ Correspondence: Gernot Zissel, Medical Center - University of Freiburg, Center for Medicine, Dept of \\ Pneumology, Hugstetter Str. 55, 79106 Freiburg, Germany. E-mail: gernot.zisselduniklinik-freiburg.de
}

@ERSpublications

In sarcoidosis, do microbes induce autoreactive T-cells by antigen mimicry? http://ow.ly/Ux0cR

Pulmonary sarcoidosis is a systemic granulomatous disease of unknown origin characterised by an increase in immune cells in the lower respiratory tract, mainly macrophages and $\mathrm{CD} 4^{+} \mathrm{T}$-cells. These cells bear signs of regular activation by a nominal antigen, and release cytokines and chemokines shaping and driving the disease progression [1].

The nature of the activating antigen, however, has been an enigma over decades of sarcoidosis research. The histological similarities between sarcoidosis and tuberculosis, and the usefulness of tuberculin preparations in the Mendel-Mantoux test, led to the search for an antigen-containing extract, and in the middle of the last century, the first "antigen" was isolated from the spleen cells of patients suffering from sarcoidosis, assuming that these cells contain the active principle inducing the disease [2-4]. However, although this preparation induces granuloma in sarcoidosis patients and has been analysed by different methods [5-7], the nature and origin of the active principle could not yet be identified.

However, in the beginning of this century, the paradigm of sarcoidosis as a "disease of unknown origin" was weakened when bacterial DNA was identified in sarcoidosis lesions [8,9]. The results presented by these authors suggest that microorganisms such as propionibacteria and mycobacteria are either the cause or at least an important cofactor in the pathogenesis of sarcoidosis.

In this issue of the European Respiratory Journal, Grunewald et al. [10] from Sweden add a new immunopathogenetic concept of sarcoidosis: they present evidence that the major histocompatibility complex (MHC) class II molecules on antigen-presenting cells contain an autoantigen that is recognised by the T-cell receptor (TCR) of the responding T-cells of sarcoidosis patients leading to their clonal expansion. This observation is a result of the long-lasting work of this group at the Karolinska Institut (Stockholm, Sweden) on the role of interactions between MHC-II and TCR in sarcoidosis. The authors were able to demonstrate that there are strong associations of MHC-II alleles and TCR subfamilies with the clinical course of sarcoidosis [11-14]. The second basis of this manuscript is the groundbreaking finding that the peptides fitting in this MHC-II groove could be self antigens with properties of autoantigens [15]. It is of interest that most of the peptides in those MHC-II grooves derive from common proteins like $\beta$-actin, haemoglobins, macroglobulins or vimentin. Interestingly, vimentin-derived peptides may serve as antigens and activate T-cells from sarcoidosis patients [16]. The current study describes that T-cells bearing the TCR $\mathrm{V} \alpha 2.3 / \mathrm{V} \beta 22$ chains accumulate in the lung of human leukocyte antigen (HLA)-DRB1* $03^{+}$patients with Löfgren syndrome. These cells show a higher expression of the early activation marker CD69 and a lower expression of CD27, a member of the tumour necrosis factor (TNF) receptor superfamily that is lost during prolonged activation, indicating that these cells have been repeatedly activated. In aggregate, they show that HLA-DRB ${ }^{*} 03$ presents an antigen to TCR V $\alpha 2.3^{+} / \mathrm{V} \beta 22^{+} \mathrm{T}$-cells. Moreover, from in silico modelling of the antigen-presenting groove, they predict that vimentin-derived molecules serve as a sarcoid antigen.

Received: Oct 302015 | Accepted: Nov 022015

Conflict of interest: None declared.

Copyright @ERS 2016 
This work has several implications and raises numerous questions. First of all, the current and the preceding publications of the Karolinska group demonstrate an autoantigenic component in the pathogenesis of sarcoidosis. However, the current report involves only patients with Löfgren syndrome and its relevance for non-Löfgren patients is not yet clear; other autoantigens might be presented in those cases. It is of interest that the HLA-DRB1 ${ }^{\star} 03$ allele is associated with good prognosis in sarcoidosis, i.e. a low rate of extrapulmonary manifestations and a remission within 2 years [17]. Although this allele is regarded as protective, seemingly in conjunction with $\mathrm{V} \alpha 2.3^{+} / \mathrm{V} \beta 22^{+} \mathrm{T}$-cells, this allele presents antigen in a way which leads to effective T-cell stimulation with consecutive antigen clearance. $\mathrm{V} \alpha 2.3^{+} / \mathrm{V} \beta 22^{+} \mathrm{T}$-cells accumulate in the lung during active, antigen-clearing disease, but cease to do so during clinical improvement [18]. Thus, this combination results in a successful immune response with final elimination of the antigen and restitutio ad integrum.

Unfortunately, there is only limited information on the reactivity of T-cells from Löfgren and non-Löfgren patients regarding the infection hypothesis (Propionibacterium acnes, mycobacteria, Mycobacterium tuberculosis catalase-peroxidase ( $\mathrm{mKatG}$ ), etc.). The authors found in an earlier work that $\mathrm{mKatG}$ stimulation of T-cells from patients with Löfgren syndrome react with a strong simultaneous release of TNF and interferon (IFN) $-\gamma$, whereas non-Löfgren patients' T-cells responded only with the release of IFN- $\gamma$ [19]. Once more, TCR V $\alpha 2.3$ T-cells react more strongly to the antigen than T-cells bearing other TCR subfamilies. It seems that at least in Swedish sarcoidosis patients, this TCR subfamily is a driver of acute sarcoidosis. Can this concept integrate the finding of a sarcoid immune response against different antigens like vimentin or $\mathrm{mKatG}$ ? The authors hypothesise that vimentin might be recognised by "molecular mimicry", i.e. that vimentin resembles the molecular structure of a microbial antigen (possibly $\mathrm{mKatG}$ ) and reactive $\mathrm{T}$-cells might cross-react to a vimentin self antigen. In fact, molecular mimicry indeed plays a role in several autoimmune or autoaggressive diseases [20]. Thus, the work presented here might give an explanation why we do see reactivity against bacterial antigens despite the fact that these microorganisms are no longer present.

There might also be a link to the genetic background of the patients. Autoantigens may derive from misfolded proteins that are insufficiently cleared. It could be demonstrated that single-nucleotide polymorphisms in the OS9 [21] and RAB23 [22] genes are associated with an increased risk of sarcoidosis. Both genes are assumed to be involved in the regulation of the degradation of misfolded proteins or the generation of autophagosomes. Thus, it can be assumed that a genetically caused malfunction of these proteins results in an increased occurrence of potential autoantigens.

Assuming that molecular mimicry is a mechanism driving T-cell activation into an autoimmune pathway in Löfgren syndrome, the fact that this disease is self-limiting is astonishing. Most of the autoimmune disorders are progressing diseases; however, as noted by the authors, there are also examples of self-limitation in diseases with an autoimmune pathogenesis. Possibly the antigen itself plays a decisive role. Vimentin is a protein in the cytoskeleton of mesenchymal cells like fibroblasts and endothelial cells. Thus, it should be available for T-cell stimulation by antigen-presenting cells only during necrotic loss of cells of mesenchymal origin. Immunological antigen clearance would, in this case, limit the autoantigenic pathway in sarcoidosis.

In summary, the study presented by GRUNEWALD et al. [10] introduces a new concept in sarcoidosis research and may pave the way for an understanding of sarcoidosis as a mimicry-driven autoaggressive disorder.

\section{References}

1 Zissel G. Cellular activation in the immune response of sarcoidosis. Semin Respir Crit Care Med 2014; 35: 307-315.

2 Kveim AM. En ny og spesifikk kutan-reaksjon ved Boecks sarcoid [A new and specific cutaneous reaction in Boeck's sarcoid]. Nord Med 1941; 9: 169.

Kveim A. Some remarks on the aetiology of Boeck's sarcoid. Acta Derm Venereol 1948; 28: 169.

Chase M. The preparation and standardization of Kveim testing antigen. Am Rev Respir Dis 1961; 84: 86-88.

Klein JT, Horn TD, Forman JD, et al. Selection of oligoclonal V $\beta$-specific T cells in the intradermal response to Kveim-Siltzbach reagent in individuals with sarcoidosis. J Immunol 1995; 154: 1450-1460.

6 Lindahl M, Andersson O, Ripe E, et al. Stimulation of bronchoalveolar lavage (BAL) and blood lymphocytes by Kveim antigen, tuberculin and concanavalin A in sarcoidosis. Br J Dis Chest 1988; 82: 386-393.

7 Richter E, Kataria YP, Zissel G, et al. Analysis of the Kveim-Siltzbach test reagent for bacterial DNA. Am J Respir Crit Care Med 1999; 159: 1981-1984.

8 Ishige I, Usui Y, Takemura T, et al. Quantitative PCR of mycobacterial and propionibacterial DNA in lymph nodes of Japanese patients with sarcoidosis. Lancet 1999; 354: 120-123.

9 Song Z, Marzilli L, Greenlee BM, et al. Mycobacterial catalase-peroxidase is a tissue antigen and target of the adaptive immune response in systemic sarcoidosis. J Exp Med 2005; 201: 755-767.

10 Grunewald J, Kaiser Y, Ostadkarampour M, et al. T-cell receptor-HLA-DRB1 associations suggest specific antigens in pulmonary sarcoidosis. Eur Respir J 2016; 47: 898-909. 
11 Katchar K, Wahlstrom J, Eklund A, et al. Highly activated T-cell receptor AV2S3 ${ }^{+} \mathrm{CD}^{+}$lung T-cell expansions in pulmonary sarcoidosis. Am J Respir Crit Care Med 2001; 163: 1540-1545.

12 Idali F, Wiken M, Wahlstrom J, et al. Reduced Th1 response in the lungs of HLA-DRB1*0301 patients with pulmonary sarcoidosis. Eur Respir J 2006; 27: 451-459.

13 Grunewald J, Eklund A, Olerup O. Human leukocyte antigen class I alleles and the disease course in sarcoidosis patients. Am J Respir Crit Care Med 2004; 169: 696-702.

14 Gulwani-Akolkar B, Posnett DN, Janson $\mathrm{CH}$, et al. T cell receptor V-segment frequencies in peripheral blood T cells correlate with human leukocyte antigen type. J Exp Med 1991; 174: 1139-1146.

15 Wahlstrom J, Dengjel J, Persson B, et al. Identification of HLA-DR-bound peptides presented by human bronchoalveolar lavage cells in sarcoidosis. J Clin Invest 2007; 117: 3576-3582.

16 Wahlstrom J, Dengjel J, Winqvist O, et al. Autoimmune T cell responses to antigenic peptides presented by bronchoalveolar lavage cell HLA-DR molecules in sarcoidosis. Clin Immunol 2009; 133: 353-363.

17 Darlington P, Gabrielsen A, Sorensson P, et al. HLA-alleles associated with increased risk for extra-pulmonary involvement in sarcoidosis. Tissue Antigens 2014; 83: 267-272.

18 Grunewald J, Janson $\mathrm{CH}$, Eklund A, et al. Restricted $\mathrm{V} \alpha 2.3$ gene usage by $\mathrm{CD}^{+} \mathrm{T}$ lymphocytes in bronchoalveolar lavage fluid from sarcoidosis patients correlates with HLA-DR3. Eur J Immunol 1992; 22: 129-135.

19 Wiken M, Ostadkarampour M, Eklund A, et al. Antigen-specific multifunctional T-cells in sarcoidosis patients with Lofgren's syndrome. Eur Respir J 2012; 40: 110-121.

20 Cusick MF, Libbey JE, Fujinami RS. Molecular mimicry as a mechanism of autoimmune disease. Clin Rev Allergy Immunol 2012; 42: 102-111.

21 Hofmann S, Fischer A, Nothnagel M, et al. Genome-wide association analysis reveals 12q13.3-q14.1 as new risk locus for sarcoidosis. Eur Respir J 2013; 41: 888-900.

22 Hofmann S, Fischer A, Till A, et al. A genome-wide association study reveals evidence of association with sarcoidosis at 6p12.1. Eur Respir J 2011; 38: 1127-1135. 